\title{
Exploring Teachers' Role Identity among Iranian EFL Teachers: A Narrative-based Research
}

\author{
Rahman Sahragard \\ Shiraz University, Shiraz, Iran \\ E-mail: rahman.sahragard@gmail.com \\ Moslem Sadeghi (Corresponding author) \\ Shiraz University, Shiraz, Iran \\ E-mail: sadeghim1354@yahoo.com
}

Received: 17-11-2016

Published: 01-07-2017
Accepted: 10-01-2017

doi:10.7575/aiac.ijalel.v.6n.4p.11
Advance Access Published: April 2017

URL: http://dx.doi.org/10.7575/aiac.ijalel.v.6n.4p.11

\begin{abstract}
The aim of this study was to explore the concept of role identity among Iranian English language teachers. Narrative inquiry was adopted as an approach of the study. Twenty-one Iranian English language teachers from three educational contexts (university, school, and institute) were interviewed and provided their written narratives. Then, the collected data were analyzed through thematic analysis and credibility and trustworthiness of the data were ensured through data triangulation and coding agreement. Results of the study revealed that Iranian EFL teachers conceptualized their role identity from multi-dimensional perspectives, including managerial, professional, and socio-cultural perspectives. The findings also showed that thirteen sub- role identities were explored and emerged under three main themes of role identity for Iranian EFL teachers. The three main themes included teachers' role identity as manager, professional, and acculturator and the thirteen sub-role identities consisted of 'knowledge transmitter, trader, juggler, interaction supervisor, promoter, arbiter, entertainer, pundit, collaborator, learner, social panacea, cultural adapter, and tutelageprovider'. The results of the current study can be useful for policy makers, teacher educators, and evaluators to have a better judgment and make appropriate decisions about teachers. Finally, the limitation of the study along with suggestion for the further research were also discussed.
\end{abstract}

Keywords: Iranian EFL teachers, Narrative inquiry, Role identity, Thematic analysis

\section{Introduction}

One controversial issue in every educational system is the role of teachers as persons who perform an undeniable and pivotal role in that educational system. Scholars in different disciplinary fields including, philosophy, sociology, psychology, anthropology, and applied linguistics have considered the notion of identity in their studies (Clark, 2013; Farrell, 2008; Noonan, 2007; Norton 2013). Norton (2013) defines the notion of identity as "how a person understands his or her relationship to the world, how that relationship is structured across time and space, and how the person understands possibilities for the future" (p. 45). The notion of teachers' identity stands for how teachers recognize their own beliefs, assumptions, attitudes, and values (Kumaravadivelu, 2012). On the other hand, a role as a concept considers the functional side of people and it refers to the statues and positions of the people in the specific community or group (Arikoski1999). For the first time the synthesized term -teacher role identity- was coined by Farrell and it is defined as "how teachers recognize their roles within their world and involves their beliefs, values, and assumptions about teaching and being a teacher" (Farrell, 2008, p. 55).So, in every educational context, the notion of identity and role is conceived by teachers and teacher educators as a synthesized term which considers the psychological, sociological, and functional sides of teachers.

Nowadays, English language is used by more people as their second language (ESL) or foreign language (EFL). Roughly, $80 \%$ of English teachers around the world are estimated Non- Native Speaker (NNS) and these NNS teachers have different identities and bring their identities to language pedagogy (Canagarajah, 1999). In Iran as an EFL context, thousands of English language teachers are working in the educational system with each one of them having different identities, but little attention has been paid to the subject of identity construction. The other problem is how these teachers synthesize this process of identity construction with their role as teachers. Whereas role identity as a multiaspect phenomenon encompasses several domains of pedagogical area, including psychological, sociological, cultural, and ideological domains, considering role identity just from one's view point is misleading. Although a lot of studies have been conducted in both EFL and ESL contexts (e.g. Bijaared, Verloop, \& Vermunt, 2000; He \& Lin, 2013; Farrell, 2011; Watson, 2006), there is a paucity of research on this subject in Iran as an EFL context. Therefore, by considering the nature of teacher role identity, this subject provides an opportunity for language teachers and teacher educators to 
think about "who of teaching and how teachers construct and reconstruct their views of their roles as language teachers and themselves in relation to their peers and their context" (Farrell, 2011, p. 54).

\subsection{Theoretical Framework of the Study}

Several frameworks have been suggested for the subject of teachers' role and identity. For example, Gee (2000-2001) assigned four components for the notion of identity, i.e. 'nature-identity, institutional-identity, discursive-identity, and affinity-identity'. In Gee's framework, identity was viewed as a multidimensional and dynamic process in which it was constructed and developed across different time and contexts. Gee's model as an analytical tool provides an opportunity to the teachers to seek and investigate their own identities in educational contexts from both theoretical and practical dimensions. Wenger (1998) proposed 'community of practice' as a model to examine the process of identity formation. In Wenger's model, community of practice includes a group of people who seek mutual aims, share a common profession or enterprise, and develop themselves personally or professionally. In this community, belonging to teachers' professional community helped teachers to construct their own identity. Bijaared, Verloop, and Vermunt (2000) introduced teachers' identity model based on what teachers do by examining teachers' professional identity from three angles of expertise, such as 'subject matter, pedagogical and didactical expertise'. Beijaard et al. (2000) believed that traditional view to "a conception of teaching takes insufficient account of the complexity of teaching, and new conceptions of the teacher as classroom manager, facilitator of learning, etc. are acknowledged" (p. 751). They also emphasized that teachers should think about what model works and what model does not work in their teaching.

Moje and Luke (2009) investigated how teacher identity could be shaped within the literacy context and how this identity construction might be related to literacy. They looked at identity and literacy as an interconnected and interrelated matter in which each one impacts on the other. Therefore, they founded their framework based on five identity conceptions known in the literature. These identity conceptions are: (a) identity as a sense of subjectivity; (b) identity as a difference; (c) identity as a consciousness process; (d) identity as a kind of position; and (e) identity as a kind of narrative act. Farrell (2011) examined the notion of role identity among 3 ESL teachers in Canada. He constructed his framework to 3 main categories for teachers' role identity as follows: (a) teacher as a manager which considers how a teacher strived to manage what happened in the classroom and this main role identity sub-categorized to communication controller, vendor, entertainer, presenter, motivator, juggler, and arbitrator; (b) teacher as a professional which deals with how a teacher dedicates himself or herself to his/her work, and takes it very seriously and sub-categorized to learner, collaborator, and knowledgeable person; and (c) teacher as an acculturator which denotes that "where the teacher is seen as one who engages in activities outside the classroom and helps students become accustomed to the local culture" (Farrell, 2011, p. 58) and sub-divided into social worker, care-provider, and socializer.

As evident from the abovementioned frameworks, Farrell's framework has some priorities over the other frameworks. This model tried to provide a comprehensive view toward the subject of teachers' role identity from multi-dimensional perspectives, such as managerial, professional, and socio-cultural aspects. In the current study, the researchers kept 3 main categories of Farrell's framework as fixed categories and tried to explore and re-conceptualize emergent subcategories for Iranian EFL teachers in a local context rather than ESL or native contexts.

\section{Review of Literature}

Review of the literature on the topic of teacher identity shows that a large number of studies have been conducted in both ESL and EFL contexts. These researches have concentrated on different dimensions of identity, such as personal, professional, social, etc.

Regarding teachers' personal identity, teachers' prior experiences at school had a significant effect on teachers' identity construction and performing their own teaching (Mayer, 1999). For James-Wilson (2001) the relationship between professional and personal identities was identified by considering how teachers feel about their students and themselves. In this way, teachers' prior experience as learners in classroom help them to construct their identity (Johnson, 2009). Ben-Peretz, Mendelson, and Kron (2003) investigated how teachers perceived their professional roles in the classroom and how they connected these perceptions to their self-image. They concluded that teachers perceived themselves in terms of their interactions with others, such as principals, students, and students' parents and their self-image were also constructed by their practical experiences. For Wright (1987), teacher's role identity could be realized through social behaviors and it is always under the construction. Hawkins and Norton (2009) allocated to teachers as social mediators in which teachers played the significant role in the construction of learners' assumptions, beliefs, and values. Duff and Uchida (1997) viewed teachers' role identity from cultural perspective and assigned the role of cultural workers to teachers.

During the past three decades, there have been a great tendency among researchers to use teachers' personal narrative as a way to conduct their studies on the subject of teacher identity construction (Connelly \& Clandinin, 1999; Watson, 2006). Connelly and Clandinin (1999) adopted a narrative approach to investigate teachers' professional identity. The findings of their study revealed that there were multiple identities for teachers and administrators depending on different life and social situations (e.g. at home, work, and with friends). So, the notion of professional identity was interconnected with temporal and spatial entity. Watson (2006) employed teacher narratives as a tools to analyze the process of professional identity construction in teachers. The results of her study illustrated that there were both positive and negative resources, such as integrate knowledge, practice, and content within educational discourses which helped teachers to form their professional identities. In this way, telling the story acted as a means in which teachers reflected on their previous experiences and shaped their professional identities. 
In an EFL context, Fisherman (2015) investigated the relationship between burnout and professional identity among 3 different groups of school teachers in Israel as an EFL context. The results revealed that there was a relationship between burnout and professional identity regarding various factors, such as sense of mission, career choice confidence, and professional efficacy. In Iran as an EFL context, a case study was conducted by Abednia (2012) in order to investigate how the process of teachers' professional identity construction could be affected by a critical teacher education course. The results of his study indicated that Iranian EFL teachers shifted: (a) from conformity to critical autonomy; (b) from no orientation to transformative orientation; (c) and from a linguistic view to an educational view in their education. In another study in Iran, Masoumpanah and Zarei (2014) obtained the results from their study that Iranian EFL teachers had a great sense of professional competence and identity in their own language teaching. In this study, Iranian EFL teachers perceived their teaching as a respectable job in the society and they had a tendency toward 'standard English' which influenced on their professional identity.

Although extensive studies have been done in the area of teacher's identity and professional identity in both EFL and ESL contexts (e.g. Bijaared, Verloop, \& Vermunt, 2000; Fisherman, 2015; He \& Lin, 2013; Watson, 2006), there is a paucity of research conducted on the nature of role identity from a multi-dimensional perspective in Iran as an EFL context. In this EFL context, the role of Iranian teachers has just limited to examine or instruct their learners in the classroom. Because the nature of role identity is multi-dimensional which encompasses several subjects in pedagogical milieus, such as social, cultural, psychological, and ideological dimensions, viewing the role identity from just one point of view is misleading. Therefore, by conducting the current study, the researchers hope to help to the field of EFL teacher education by considering teachers' role identity from professional, managerial, and socio-cultural perspectives.

The current study pursued to explore the concept of role identity among Iranian EFL teachers. The study took into consideration triple dimensions of Iranian EFL teachers' role identity, i.e. managerial, professional, and socio-cultural dimensions. To achieve these aims, two questions were addressed: (1) how the notion of role identity is conceptualized by Iranian EFL teachers? And (2) how do Iranian EFL teachers perceive their role identity as managers, professionals and acculturators?

\section{Method}

Narrative inquiry as a new trend of research in qualitative approach has been taken into consideration by several disciplines, such as psychology, sociology, and education. In education, narrative research was used to investigate teachers' professional lives (Barkhuizen, Benson, \& Chick, 2014; Connelly \& Clandinin, 1999; Watson, 2006). Clandinin and Connelly (1994) believe that narrative is both method and phenomenon.

In recent years, there has been a great tendency among researchers to conduct their studies through narrative inquiry pertaining to the topic of self and identity. In concert with this perspective, Giddens (1991) emphasized that narrative is acquired in post-modernity as a resource that individuals draw upon in the construction of social. He argued that "selfnarratives, or the stories people tell about themselves, help us to understand the ways in which individuals situate themselves and their activities in the world" (as cited in Barkhuizen et al., 2014, p. 2). Farrell (2011) suggested that "teachers can articulate their roles through their biographies, stories, and diaries and share with other teachers as they begin to construct and reconstruct their teaching worlds" (p. 60). Barkhuizen et al. (2014) classified the prior conducted studies through narrative inquiry in the field of language pedagogy to five categories, i.e. language memoirs, studies of language memoirs, autobiographical case studies, biographical case studies, and studies of multiple narratives. What differentiated these five categories from each other is the role of the researcher, the number of participants, and the instrument for data gathering and data analysis. In studies of multiple narratives, "the number of participants can vary from two to several hundred ... and the narratives are usually written and the researchers play no role in their construction, other than giving the writers instructions on what they should write about" (Barkhuizen et al., 2014, p. 9). Whereas the number of participants in the current study was more than two and the researchers used oral and written narratives of participants as data in order to understand Iranian EFL teachers' beliefs, assumptions, perceptions, and values, studies of multiple narratives as a type of narrative inquiry in the field of language pedagogy was adopted to conduct the current study. By employing studies of multiple narratives, the researchers benefited from another narrative term, i.e. analysis of narrative to conduct the present study. Polkinghorne (1995) distinguished between "narrative analysis" and "analysis of narratives". While the former deals with "research in which storytelling is used as a means of analyzing data and presenting findings, the latter refers to research in which stories are used as data" (p. 3). Therefore, the researchers conducted this study based on narrative research "because it helps us to understand the inner mental worlds of language teachers ... and the nature of language teaching ... as social and educational activity" (Barkhuizen, et al., 2014, p. 2).

\subsection{Participants}

Those Iranian EFL teachers who were accessible (convenient sampling) were recruited as the sample. Although 23 English language teachers participated in the current study, 2 teachers withdrew from the study later. So, the data related to them were discarded. Finally, 21 Iranian English language teachers remained in the study. The participants were both male and female with different work experiences, work statues, majors (e.g. English language teaching, English literature, and English translation), and educational degrees (e.g. B.A., M.A., and Ph.D). The participants were from 5 main geographical districts (west, east, center, north, and south) of Iran and they were from 3 educational contexts, i.e. schools ( 6 teachers), universities ( 5 teachers), and language institutes (10 teachers). To shy away from any ethical violation, the participants were agreed to take part in the study by signing the consent form. The participants were informed of the objectives of the study and they were also assured that their privacy would be kept confidentially. 


\subsection{Instrumentation}

Two instruments, i.e. interview and written narrative were utilized to collect the data in the current study.

\subsubsection{Interview/oral narrative}

In narrative inquiry, the term interview equates with oral narrative (Barkhuizen, et al., 2014). To obtain rich information, the semi-structured interview as a common tool in language pedagogy research was adopted to conduct the current study because this type of interview "gives a certain degree of flexibility so that as the interview progresses the interviewer will ask follow-up questions for interviewees to clarify or elaborate" (Barkhuizen, et al., 2014, p. 17). By employing interview as an instrument, the researchers attempted to elicit data related to Iranian teachers' perceptions, values, beliefs, and attitudes about their professional identity. This was in line with this statement that "interviews are used to gather data from people about opinions, beliefs, and feelings about situations in their own words" (Ary, Jacobs, Sorensen, \& Walker, 2014, p. 466). Therefore, 21 Iranian EFL teachers were interviewed until no new information was forthcoming (data saturation). Fifteen participants were interviewed face-to-face and the rest (six participants) were interviewed online.

Before the participants were interviewed, the researchers considered several matters, such as, preparing interview guide, designing a consent form, choosing a quiet and comfortable place for interview, and confirming the time and date of the interview with each interviewee. The length of interview for each participant was about 30 minutes and the total length for all interviews was about 10 hours. The interviews were held in English language and the stream of each interview was concentrated on the subject of Iranian EFL teachers' role identity (see appendix). As a complementary support to the interview section, the participants had to provide a written narrative about their professional life.

\subsubsection{Written narrative}

Several researchers have employed written narrative as an instrument in their research to investigate teachers' identity construction (Casey, 1995; Connelly \& Clandinin, 1999; Watson, 2006). In the current study, written narrative in the form of teachers' personal narrative about their teaching was used as another instrument to elicit Iranian teachers' professional life and their stories about their job.

In order to obtain the aims of the study, the researchers asked the participants to write about their professional life by thinking and reflecting about their own previous and current teaching. Writing a narrative provided an opportunity for teachers to think deeply about their own identities as a teacher. The written narrative had to be written around the topic of teachers' role identity and be relevant to the subject of interview. Each participant was asked to write his/her narrative in the English language and to email it to the researchers. The time assigned to send these narratives was two weeks after each interview; however, some narratives were received one or two weeks with delay. The length of each received narrative varied from 400 words to 900 words.

\subsection{Data collection and analysis}

The process of data gathering was done between August 2015 and November 2015. Data triangulation and member check were employed to guarantee the credibility of the study. In data triangulation, the researcher considers whether the gathered data through one instrument is confirmed by the other instrument (Ary et al., 2014). In the current study, the collected data through interview/oral narrative were confirmed by the gathered data through written narrative. The member check was also utilized by participants' feedback for accuracy and meaning to guarantee the credibility of the study. To meet the trustworthiness or dependability of the research, code-recode (intra-rater) and inter-rater were employed. To achieve the intra-rater agreement in the current study, the researchers coded some parts of the data and left it for a period of time. Then, they recoded the data again and subsequently compared the two sets of coded data. To obtain inter-rater agreement, the researchers asked an assistant professor in applied linguistics to code and label some selected parts of transcriptions. Then, the researchers compared inter-rater codes and labels with their own codes and labels. Finally, the researchers found that the codes and labels had 0.90 similarities with the inter-rater's codes and labels.

The gathered data in the form of written and oral narratives were analyzed through thematic analysis as an approach of analysis in the current study. Thematic analysis involves "repeated reading of the data, coding and categorization of data extracts, and their reorganization under thematic headings" (Barkhuizen, et al., 2014, p. 75). So, the researchers conducted repeated reading of the data and moved back and forth between the data. In the first step, the data were codified in which the data were broken down into pieces and labeled into core categories. The transcribed and written narrative data were coded and labeled based on the key terms and key phrases used by participants which characterized each domain of teachers' role identity. The codifications were done based on the literature and the theoretical frameworks, including the work of Wright (1987), Wenger (1998), Gee (2000-2001), Farrell (2011), and Kummaravadivelu's (2012). The purpose of this step was to develop core concepts, properties, and categories (Ary et al. 2014). In the second step, the broken data were put together and connections were made between categories and their subcategories. In this step, all of the explored domains of identities were classified under their related sub-categories. Then, the connections between these sub-categories and three main categories (determined in advance based on Farrell's (2011) framework) were identified. In the final step, the categories were reorganized together under the thematic heading of role identity. In this step, all of the explored sub-categories and 3 predetermined main categories for Iranian EFL teachers were reorganized together under the thematic heading of role identity (RI). 


\section{Results and Discussion}

Results of the current study revealed that 13 sub-role identities were explored for Iranian EFL teachers. These 13 subrole identities were reorganized under 3 main themes. In order to save the page in this paper, the researchers presented 6 sub-role identities from the interviews/ oral narratives and 7 sub-role identities from the written narratives as evidence. To keep the privacy of the participants confidentially, the researchers assigned the codes for each participant. In the current study, the codes of $\mathrm{UT}_{1-5}, \mathrm{ST}_{1-6}$, and $\mathrm{IT}_{1-10}$ were allocated to university teachers, school teachers, and language institute teachers, respectively. In the following, 3 main themes for Iranian EFL teachers' role identity along with their sub-role identities are presented:

\subsection{Teacher as a manager}

Teacher as a manager dealt with how a teacher manages his/her classroom (Farrell, 2011). In the current study, Iranian EFL teachers allocated 7 managerial role identities to themselves, including interaction supervisor, knowledge transmitter, juggler, promoter, arbiter, trader, and entertainer. Each of these 7 sub-role identities and their related evidence is discussed in the following:

\subsubsection{Interaction supervisor}

Iranian EFL teachers conceptualized themselves as supervisors who managed or conducted the interactions between students - students and teacher -students in the classroom.

An institute teacher with 10 years of teaching experience in language institute answered the question (how do you manage or control the stream of communication in your classroom?), with this statement:

$\mathrm{IT}_{3}$ : I think we should talk about the role of the teacher as a leader... Ah... I act as an Orchestra leader in my class....Um... When my students communicate or interact with each other. I do this ... but not actually interrupt my students' interactions... Right ...So, I let them do their jobs whenever I think or feel they are in the wrong way... Then... I try to control them.

As shown in this oral narrative/interview, the institute teacher conceived his role identity as an 'orchestra leader' to manage the stream of communication in the classroom. He believed that the teacher should not interfere with the stream of communication unless the students had a problem. So, he conditioned his presence in the communication when there was a difficulty.

\subsubsection{Knowledge transmitter}

Iranian EFL teachers not only transmitted their knowledge to the students but also delivered the information to their students.

From the written narratives, an institute teacher with 4 years of teaching experience assigned this sub-role identity to herself in doing their work as follows:

$\mathrm{IT}_{9}$ : As a teacher who spend a years to teach language to adults and children, I have always attempted to provide knowledge and materials for my learners. These years of my teaching have accompanied with providing a good 'Package' for learners. When my learners have opened this 'Package' they have surprised because they have been encountered with a lot of new subjects....

As shown in this written narrative, the institute teacher narrated her role identity as one who provided and presented a pre-package knowledge and materials to her students.

\subsubsection{Juggler}

Iranian EFL teachers provided multi-tasks simultaneously for students to increase students' creativity.

In the following, an English language institute teacher assigned the role of juggler to herself in managing her classroom:

$\mathrm{IT}_{5}$ : Last week, I ask learners to bring summary for each reading and also say that summarize and underline grammatical points in it, so in one text they can practice on their writhing, speaking and also grammar points at the same time. I believe in this attitude and engaging my students in different tasks at the same time which increase their creativity.

As indicated in the above written narrative, the teacher had a tendency to engage her learners simultaneously in several tasks, such as writing, speaking, and focusing on grammar rather than uni-task. She also asserted that this could increase the creativity of learners.

\subsubsection{Promoter}

It stands for Iranian EFL teachers' role identity who promoted and encouraged students pertaining to their activities in the classroom.

To vouch for this concept, an English language institute teacher with 8 years of teaching experience assigned promoter as a role identity for himself as follows:

$\mathrm{IT}_{8}$ : I always do my best in trying to promote my students by encouraging them, thanking them, giving them extra bonuses, etc. to keep them on the right track.

As revealed in the written narrative, the teacher narrated how he encouraged his students by several motivations, such as giving extra bonuses and thanking them. 


\subsubsection{Arbiter}

Iranian EFL teachers judged their students' performance in the classroom and gave them appropriate feedbacks when they make mistakes.

An institute teacher who had 8 years of teaching experience and worked as a permanent teacher answered the question (how do you correct your students' mistakes in class?), as follows:

$\mathrm{IT}_{8}$ : Most of the time I usually wait because of peer correction... Sometimes they correct themselves... Um... If they can't correct themselves ask one of the student do that and... If neither of them...Ah... I have to make sure that I give them the right feedback.... Not for all of the mistakes ...Um...Given the feedback for all mistakes can be so harsh.

As understood from this interview/oral narrative, the institute teacher judged his students' mistakes by giving appropriate feedbacks to them when it was necessary.

\subsubsection{Trader}

This sub-role identity refers to how Iranian EFL teachers viewed their job from financial point of view and acted as persons who wanted to trade their teaching.

A university teacher with 8 years of teaching experience referred to the role of trader in her job with the following statement:

$\mathrm{UT}_{5}$ : Teachers in Iran, despite other countries, are known as a stratum which is underpaid. I don't see my job as a cash machine but equal pay for what I do may impact on the quality of my work.

As indicated in the written narrative, the university teacher complained about her payment and put her emphasis on an undeniable role of money on her job.

\subsubsection{Entertainer}

It refers to the sub-role identity of Iranian EFL teachers who tried to entertain their students when the atmosphere of the class was boring.

A school teacher who had 19 years of teaching experience and worked as a permanent teacher responded the question (do you entertain your students in your class?), as follows:

$\mathrm{ST}_{6}$ : Part of our language teaching as we have studied and know about it... I mean entertaining... is a part of fun activity and you should give student some entertainments... Some activities... May be give them more relax... More comfortable. I tell some jokes sometimes and ... I ...I say ...I show and say some fun stories...Fun stories about myself, political characters, movies' character... Some things like this.

As revealed in this excerpt, the school teacher insisted on entertaining his students in the classroom by several activities, including telling jokes and fun stories.

\subsection{Teacher as a professional}

Teacher as a professional referred to how a teacher conceives her /his job from professional view point and a teacher takes her/his teaching seriously (Farrell, 2011). In the current study, Iranian EFL teachers assigned three professional role identities to themselves, including 'pundit, collaborator, and learner'. In the following, each of these sub-role identities is presented and discussed:

\subsubsection{Pundit}

Iranian EFL teachers conceptualized themselves as teachers who had profound knowledge about their teaching.

From the written narratives, the narrative of a female university teacher with 8 years of teaching experience is presented as evidence in the following:

$\mathrm{UT}_{4}$ : When I compare the current level of my knowledge to three or four years ago, I am so happy and I can say I learn a lot of the subjects about my own field, I mean my teaching. I remember those days that I was incapable and feeble in both my general and professional knowledge. Now, I am proud of myself for acquiring an acceptable knowledge about my major. I can say I have a profound knowledge about the different methods of teaching and learning, about how to do a research in my field, and about how to teach my students. It would have been realized just by hardworking and burning the midnight oil.

As indicated in above written narrative, the university teacher perceived herself as one who had a profound knowledge about her field.

\subsubsection{Collaborator}

Iranian EFL teachers assigned the sub-role identity of collaborator to themselves by negotiating their knowledge with colleagues and cooperating with colleagues in academic's matters.

In the following, a written narrative of a university teacher who allocated the role of collaborator to himself in his teaching is presented:

$\mathrm{UT}_{2}$ : Since I have worked as an observer, my important role seems to be that of the collaborator. In the post observation conferences and the staff meetings we have, I always try to provide the teachers with the necessary points on teaching and testing. 
As shown in this written narrative, the university teacher recounted his role as one who shared his professional knowledge with his colleagues in different situations.

\subsubsection{Learner}

It stands for the sub-role identity of Iranian teachers who not only taught their students but also learnt from them.

A female university teacher with 13 years of teaching experience responded the question (do you think that you can learn from everyone, e.g. colleague or learner?), as follows:

$\mathrm{UT}_{1}$ : Of course, teacher can learn... Uh you know! Of course because I wanna say as sociocultural theory says teacher as a learner... So we've student not only we teach them but also learn from them we are both constructive in the class ... Ah... Teacher by learners... Learners by teacher ....Umm ... Sometimes I learn from my students.

As shown in this excerpt from oral narrative/interview, the university teacher looked at her role identity not only as a teacher, but also as a learner who could learn from her students. She backed her belief by referring to sociocultural theory which views the teacher both as a learner and a teacher.

\subsection{Teacher as an acculturator}

Teacher as an acculturator referred to socio-cultural dimension of teacher's role identity (Farrell, 2011). In the current study, Iranian EFL teachers assigned the role of acculturator to themselves in which they took into consideration both social and cultural aspects of their teaching, i.e. 'social panacea, cultural adapter, and tutelage-provider'. Evidence for each of these triple sub-role identities is presented and discussed.

\subsubsection{Social panacea}

This role denotes how Iranian EFL teachers supported their students and tried to solve students' problems both inside and outside the classroom environment.

From written narratives, a narrative of a university teacher with 7 years of teaching experience is presented as evidence.

$\mathrm{UT}_{3}$ : I am their friend and supporter and they do not hesitate to offer their learning and living problems in the classroom and sometimes out of the class in my office. I do my best as a good social advisor, as a good social supporter regarding my students. Not only in my class but also outside my class in the society. I remember that it was last year, I along with my students attended in 'Charity Organization' and we met with orphan children....

As indicated in the written narrative, the university teacher narrated her role identity as one who solved her student problems and she took part in social affairs.

4.3.2 Cultural adapter

Iranian EFL teachers observed and respected various cultural beliefs, norms, and customs. They also adjusted the cultural mismatches and differences.

An institute teacher with 10 years of teaching experience answered the question (how do you deal with cultural mismatches, e.g. about cultural norms' mismatches?), as follows:

IT $_{1:}$ Western cultural norms...This is may be in Iranian private school... Ah... Pardon! Private institutes not for schools... Especially for new books you must adapt them to the some cultural norms' mismatch.... But I mean for institute... Yes! Sometimes we have boyfriend... girlfriend... This is not adapted to our culture... So, they are omitted from the book but they are in the audio CD...Students say... They... Here in the CD... We cannot see them on the book...Ha ha ha ...

It could be implied that the institute teacher attempted to adjust the mismatches between western culture and Iranian culture by explaining these differences to his students.

\subsubsection{Tutelage-provider}

Iranian EFL teachers conceptualized themselves as teachers who had a sense of intimacy with their students and strived to be a good friend or comrade for their students.

In response to the question (do you have any sense of intimacy with your students inside or outside the class?), a school teacher with 25 years of teaching experience said:

$\mathrm{ST}_{1:}$ Yes as... You know for naughty students... I mean! You should be a good friend... You need to be if... If you are not, you are not easy in your class because all the time... All the time... They are talkative... Naughty boys are talkative all the time. If you are not to be a good friend for them if you are not a friend you are not easy in your class and not teach well .... Because of this you need to be a good friend especially for naughty boy... Yes! Why not... Also to be friend for the high talented, the best students .... Outside the class, you should keep this friendship...

As shown in the excerpt from oral narratives, the school teacher assumed himself as one who had a sense of intimacy with his students and he tried to keep his friendly relationship with his students.

\subsection{Discussion}

As indicated in the abovementioned oral and written narratives, 13 sub-role identities emerged under 3 main themes for Iranian EFL teachers. The first main theme of Iranian EFL teachers as manager encompassed 7 sub-role identities, including juggler, arbiter, promoter, trader, entertainer, interaction supervisor, and knowledge transmitter for the managerial roles of teachers. This main role identity took into consideration how Iranian EFL teachers conceptualized 
themselves as manager in conducting their classroom learning and teaching. The main role identity of manager and their related sub-categorizations were in line with previous studies, such as Beijaard et al. (2000), Farrell (2011), and Kummaravadivelu (2012) although one of the sub-role identity, i.e. knowledge transmitter was in contradiction with prior studies. In this way, the sub-role identity of Iranian EFL teachers as knowledge transmitters opposed to Beijaard et al., (2000) teacher expertise which denotes that the role of teacher is more than the transmitter of knowledge and Kumaravadivelu's (2012) post-modernism view to teacher identity which considered teacher as transformative intellectual.

The second main theme of Iranian EFL teachers as professional emerged from 3 sub-categories, i.e. pundit, collaborator, and learner. This main role identity considered how Iranian EFL teachers conceptualized themselves as teachers who took their job seriously, dealt with their teaching professionally, negotiated their knowledge with their colleagues, learnt from everyone in their own field, and expanded their general and professional teaching knowledge. So, the role identity of Iranian EFL teachers as professional and their related sub-divisions were supported by the literature and theoretical frameworks, such as Wenger's (1998) community of practice, Kummaravadivelu's (2012) professional knowledge, and Beijaard et al., (2000) pedagogical and didactical expertise. In Wenger's (1998) community of practice, teachers continuously shared their concerns, solved their problems, and expanded their knowledge and expertise in their own filed by interacting with each other. In this community, the identity of teachers developed through day-to-day experiences by participating in the community. In Kummaravadivelu's (2012) professional knowledge, the knowledge "represents the intellectual content of the discipline, a compilation of facts, theories, and concepts. With this concept, knowledge is shared by the members of the profession" (p. 24). So, this definition of knowledge refers to the sub-role identity of Iranian EFL teachers as pundit and collaborator which were categorized under the main theme of professional identity. For Farrell (2011), teachers have to act as both learner and teacher. In the light of Beijaard et al., (2000), teachers not only must have a profound understanding about their own subject area which leads them to develop their own identities but also should reflect on their own model of teaching and think about what model works and what model does not work in their teaching.

Lastly, the socio-cultural side of Iranian EFL teachers' role identity under the main category of acculturator was subdivided into social panacea, tutelage-provider, and cultural adapter. Although there were some differences between western culture and Iranian local context resulting in modifying and redefining the sub-role identities in this main category, findings of the current study were in agreement with the previous studies, such as Wright (1987), Duff and Uchida (1997), Wenger (1998), Hawkins and Norton (2009), Farrell (2011), and Clark (2013). In the previous studies, the role identity of teachers was defined as social mediators (Hawking \& Norton, 2009) and socializers (Farrell, 2011). In Farrell's (2011) view, the teacher acted as a care-provider or performed the role of mother or father for their students. In the current study, Iranian EFL teachers had a sense of intimacy and sympathy with students in/outside their classroom and preferred to be a good comrade/ tutelage-provider for them rather than Farrell's (2011) motherly role of teacher as a care-provider for their learners. Duff and Uchida (1997) assigned the role of cultural workers to teachers in which the teachers are involved in the transmission of culture to their students. In Clark's (2013) view, teacher's identity was assumed as a sociocultural phenomenon which emanated from a local context. In the current study in Iran as a unique context, i.e. multicultural and multiethnic, teachers had to resolve and settle disputes regarding religion, culture, ethnic, accent, customs, norms, etc. among their learners. They should also take into account the difference between their native culture and western culture. Therefore, the main role identity of Iranian EFL teachers as acculturators and their sub-divisions (social panacea, tutelage-provider, and cultural adapter) were the modified and redefined versions of teachers' role identity from the previous studies in the Iranian local context.

\section{Conclusion}

Because the nature of role identity is a multi-dimensional phenomenon which includes several domains in the pedagogical milieu, such as psychological, managerial, professional, and socio-cultural dimensions, viewing the role identity from one view point is untrue and misleading. Although a lot of researches have been done in the area of teacher's identity in ESL and native contexts, a little studies have been conducted on the subject of role identity from a multi-dimensional perspective in Iran as an EFL context. In the current study, the researchers investigated the concept of teachers' role identity from professional, managerial, and socio-cultural perspectives. The findings of study revealed that Iranian EFL teachers perceived and conceptualized their role identity as manager, professional, and acculturator. So, by conducting the present study in Iranian EFL context as a local context, a comprehensive view toward the notion of role identity regarding Iranian EFL teachers was depicted.

\subsection{Implication of the study}

The results of the current study can be useful on a number of grounds. First, the results of the present study can be useful for language pedagogy. As language teachers play a pivotal role in educational contexts, knowing about their role identities can help to the domain of language pedagogy. Second, it can also be useful for policy makers, teaching practitioners, material developers, evaluators, and teacher educators to have a better judgment and make appropriate decisions about teachers. Third, findings of the present study can give a comprehensive view about teachers' role identity in order to move away from viewing the role of teachers from one dimension and consider the multi-aspects of teachers' role identity. In this way, social, cultural, professional, and managerial role identities have to be taken into consideration in the academic milieus. Fourth, belonging to a community of practice as teachers' community can be helpful for teachers to enhance and share their knowledge with their colleagues. Fifth, the result of the current study can also be beneficial for teachers to have reflective practice about their own teaching. Finally, the finding of this study can 
be critically useful for Iranian EFL teachers' cultural, social, and ethnic norms and customs in order to shy away from wrong stereotypes associated with other cultures.

5.2 Limitation and suggestion for future research

In this narrative-based approach, the role identity as a complex human attribute was taken into consideration. Because of the complexity of the human subject, like all the social science researches the collected data in this study might have suffered from some degree of pollution. The second limitation was the generalizability or transferability of the findings. Although the researchers attempted to provide rich, detailed, and thick descriptions of the context, the generalizability or transferability of the findings was restricted to Iranian context as an EFL context due to the exploratory nature of the current study. Therefore, generalizing findings to other EFL or ESL contexts should be made with some precautions. Nevertheless narrative-based research limited its claim pertaining to generalizability of the findings, "generalization is often a matter of establishing a pattern of shared experience" in narrative inquiry (Barkhuizen, et al., 2014, p. 92).

The future study can be conducted with large population by employing a different research approach, such as survey research and a different instrument (e.g. a validated questionnaire). It can also be suggested to examine the difference between teachers' male and female role identity. The other subject can be investigated regarding the difference between university, school, and language institute teachers' role identity. In addition, the difference between experienced and novice teachers' role identity can be researched as another subject. Lastly, as Iran is a multi-ethnic country with different ethnicities, such as Kurd, Lor, Turk, Fars, Arab, etc. the ethnic differences of teachers' role identity can be investigated for further research.

\section{References}

Abednia, A. (2012). Teachers' professional identity: Contributions of a critical EFL teacher education course in Iran. Teaching and Teacher Education, 28 (5), 706-717.

Arikoski, J. (1999). Interaction in teaching. In P. Räsänen, J.Arikoski, P. Mäntynen, \& J. Perttula. (Eds.). Teaching psychology (pp. 177-223). Finland: Public Administration Training Centre Ltd.

Ary, D., Jacobs, L. C., Sorensen, C., \& Walker, D. A. (2014). Introduction to research in education (9 th ed.). USA: Wadsworth, Cengage Learning.

Barkhuizen, G., Benson, P., \& Chick, A. (2014). Narrative inquiry in language teaching and learning research. New York: Routledge.

Ben-Peretz, M., Mendelson, N., \& Kron, F. W. (2003). How teachers in different educational contexts view their roles. Teaching and Teacher Education, 19 (2), 277-290.

Beijaard, D., Verloop, N., \& Vermunt. J. D. (2000). Teachers' perceptions of professional identity: An exploratory study from a personal knowledge perspective. Teaching and Teacher Education, 16, 749-764.

Canagarajah, S. (1999). Resisting linguistic imperialism in English teaching. Oxford: Oxford University Press.

Casey, K. (1995). The new narrative research in education. Review of Research in Education, 21, 11-53.

Clandinin, D. J., \& Connelly, M. F. (1994). Personal experience methods. In Denzin, N. K., Lincoln, Y. S. (Eds.), Handbook of qualitative research, (pp. 413-427). Thousand Oaks, CA: Sage Publications.

Clark, U. (2013). Language and identity in English. London: Routledge.

Connelly, F. M., \& Clandinin, D. J. (1999). Shaping a professional identity: Stories of educational practice. New York: Teachers College Press.

Duff, P., \& Uchida, Y. (1997). The negotiation of teachers' sociocultural identities and practices in postsecondary EFL classrooms. TESOL Quarterly 31, 451-486.

Farrell, T.S.C. (2008). Reflective Language Teaching: From Research to Practice. Continuum, London: UK.

Farrell, T. S.C. (2011).Exploring the professional role identities of experienced ESL teachers through reflective practice. System, 39, 54-62.

Fisherman, Sh. (2015). Professional identity and burnout among pre-school, elementary, and post-elementary school teachers in Israel. Journal of Curriculum and Teaching 4 (1), 1-13.

Gee, J. (2000-2001). Identity as an analytic lens for research in education. Review of Research in Education. 25, 99-125.

Hawkins, M., \& Norton, B. (2009). Critical language teacher education. In Burns, A., Richards, J. (Eds.). Cambridge Guide to Second Language Teacher Education, (pp. 30-39). Cambridge: Cambridge University Press.

He, P. \& Lin, A. M. Y. (2013). Tensions in school-university partnership and EFL pre- 272 service teacher identity formation: A case in mainland China. The Language Learning Journal, 41 (2), 205-218.

James-Wilson, S. (2001). The influence of ethno-cultural identity on emotions and teaching. Annual Meeting of the American Educational Research Association. New Orleans.

Johnson, K. E. (2009). Second language teacher education: A sociocultural perspective. London: Routledge.

Kumaravadivelu, B. (2012). Language teacher education for a global society. UK: Routledge. 
Masoumpanah, Z., \& Zarei, Gh. (2014). EIL, Iranian teachers' professional identity and perception of professional competence. International Conference on Current Trends in ELT, Procedia - Social and Behavioral Sciences, 98,1100 $-1109$

Mayer, D. (1999) Building teaching identities: Implications for pre-service teacher education. Paper presented to the Australian Association for Research in Education, Melbourne.

Moje, E., \& Luke, A. (2009). Literacy and identity: Examining the metaphors in history and contemporary research. Reading Research Quarterly, 44 (4), 415-437.

Noonan, H. W. (2007). Identity eliminated. Analysis, 67, 122-127.

Norton, B. (2013). Identity and language learning: Extending the conversation (2nd ed.). Bristol, UK: Multilingual Matters.

Polkinghorne, D. E. (1995). Narrative configuration in qualitative analysis. Qualitative Studies in Education, 8(1), 5-23.

Watson, C. (2006). Narratives of practice and the construction of identity in teaching. Teachers and Teaching: Theory and Practice, 12 (5), 509-526.

Wenger, E. (1998). Communities of practice. Learning, meaning and identity. Cambridge: Cambridge University Press. Wright, T. (1987). Roles of teachers and learners. Oxford: Oxford University Press.

\section{Appendix}

(1). How do you manage your classroom?

(2).What is the role of financial matters or money in your work?

(3). Do you look at your teaching as goods that you want to sell?

(4). How do you manage the stream of communication in your classroom?

(5). Do you entertain your students in your class?

(6). Do you look at your teaching as a matter of fun?

(7). Do you promote or encourage your students in the classroom? How?

(8). Do you engage your learners simultaneously at several tasks or only on one task?

(9). Do you assume yourself as a teacher who only delivers information or knowledge to students?

(10). Do you judge your student performance? How?

(11). How do you provide an appropriate feedback for your learner?

(12). Do you think that the process of teaching is related to both learning and teaching?

(13). Do you think that you can learn from everyone (colleague or learner)?

(14). Do you perceive yourself as a knowledgeable person in your own field?

(15). Do you share or negotiate your teaching knowledge with your colleagues?

(16). How do you deal with your students' problems?

(17). Do you support your students outside of the class?

(18). Do you provide advice for your students regarding their problems inside or outside the classroom?

(19). Do you have any sense of intimacy with your students inside or outside the class?

(20). Do you believe that 'western culture' should be taught along with teaching the English language?

(21). How do you deal with cultural mismatches?

(22). How do you preserve your own norms, values and beliefs along with western cultural norms, values, and beliefs? 